\title{
Students' School Engagement and Their Truant Behavior: Do Relationships with Classmates and Teachers Matter?
}

\author{
Selina Teuscher ${ }^{1} \&$ Elena Makarova ${ }^{1}$ \\ ${ }^{1}$ School of Education, University of Applied Sciences and Arts Northwestern Switzerland, Solothurn, Switzerland \\ Correspondence: Elena Makarova, School of Education, University of Applied Sciences and Arts Northwestern \\ Switzerland, Solothurn, Switzerland, Obere Sternengasse 7, CH-4502 Solothurn. Tel: 41-32-628-6734.
}

Received: August 27, 2018

Accepted: September 18, 2018

Online Published: September 27, 2018

doi:10.5539/jel.v7n6p124

URL: https://doi.org/10.5539/jel.v7n6p124

\begin{abstract}
Research on school dropout suggests that the decision to drop out of school is not a sudden or immediate one, but rather the result of a long-term process of withdrawal from school. While school engagement and truancy are among the most prominent constructs to be associated as precursors of school dropout, the relationship between these two constructs needs further analysis. Our study establishes more comprehensive understanding of school engagement and truancy by focusing on students' individual characteristics and their relationships in school, particularly the student-teacher relationship and relationships with peers. It demonstrates that among the individual characteristics the migration background is crucial for school engagement, while the student age is important for truancy. Furthermore, peer-relationships are positively related to students' school engagement, but not to their truancy. Furthermore, a good student-teacher relationship not only has positive impacts on students' school engagement, but is also negatively associated with truancy, while school engagement mediates this path.
\end{abstract}

Keywords: relationships with peers, school dropout, school engagement, student-teacher relationship, truancy

\section{Introduction}

One of the pressing topics for educational equity in OECD countries is early school leaving or school dropout. Students who do not complete their post-compulsory education are at risk of societal exclusion because the successful completion of secondary education leads to better jobs and healthier lifestyle prospects (OECD, 2012). In line with this, a review study by Lamb and Markussen (2011, p. 5) shows that despite some contextual differences all definitions of school dropout share the understanding that a dropout is 'a person who is no longer at school and does not hold an upper secondary qualification'. In Switzerland, as in other European countries, the term school dropout describes an 18- to 24-year-old person who has not successfully completed post-compulsory education and has not begun another type of training (Lamb \& Markussen, 2011). In the European Union, the rate of school dropout varies greatly between different countries with an average rate of $12.7 \%$ (European Commission, 2013). However, 'the share of early school leavers among foreign-born is on EU average more than twice as high as for natives (25.4\% compared to 11.5\%)' (European Commission, 2013, p. 7). Similarly, the dropout rate in Switzerland differs greatly according to students' origins. Among youth who were born in Switzerland the dropout rate is $6 \%$, whereas among students who were born abroad this rate attains $13.8 \%$ (Federal Statistical Office (FSO), 2018). The high dropout rate among students with an immigrant background compels researchers to gain a more comprehensive understanding of reasons for school dropout, in order to make the education systems in European countries more inclusive for heterogeneous student populations.

\subsection{Research on School Dropout and Its Precursors}

Research on school dropout reveals that the decision to drop out of school is not a sudden or immediate one (Stamm, 2012), but rather the result of a long-term process of withdrawal from school (Alexander, Entwisle, \& Horsey, 1997). Thus, in order to understand this process, it is much more important to study the gradual withdrawal from school than the final step of dropping out (Lamb, 2011). In contemporary research, there are various theoretical approaches to analyze the process of gradual withdrawal from school. The concept of hidden school dropout focuses on psychological absenteeism from school and states that students can be physically present at school, but distance themselves mentally from it (Makarova \& Herzog, 2013; Sultana, 2006). The approach of school alienation focuses on a multidimensional set of negative attitudes towards social and academic domains of school including cognitive and emotional elements (Hascher \& Hadjar, 2018; Morinaj, 
Scharf, Grecu, Hadjar, Hascher, \& Marcin, 2017). Finally, school engagement is one of the most prominent constructs associated as precursors of school dropout (Rumberger \& Ah Lim, 2008). School engagement is defined as 'the student's psychological investment in and effort directed toward learning, understanding, or mastering the knowledge, skills, or crafts that academic work is intended to promote' (Newmann, Wehlage, \& Lamborn, 1992, p. 12).

Research on school engagement is relatively young (Appleton, Christenson, \& Furlong, 2008) and therefore 'school engagement as a topic of investigation and educational practice is yet to emerge' (Furlong et al., 2003, p. 100). Despite the ongoing dispute with respect to the theoretical model, definition and assessment of school engagement (Furlong et al., 2003; Fredricks, Blumenfeld, \& Paris, 2004; Jimerson, Campos, \& Greif, 2003; Reschly \& Christenson, 2012), researchers concur that school engagement is a multidimensional construct that combines behavioral, emotional and cognitive aspects (Fredricks et al., 2004; Fredricks, Blumenfeld, Friedel, \& Paris, 2005; Wang \& Eccles, 2013; Wang, Willet, \& Eccles, 2011).

With respect to school dropout, a review study by Rumberger and Ah Lim (2008) reported that over two-thirds of the studies analyzed found a relationship between school engagement and dropout in high school, while higher levels of school engagement reduced the probability of dropping out or increased the probability of graduating. Correspondingly, Henry, Knight and Thornberry (2012) as well as Fall and Roberts (2012) provided empirical evidence that school disengagement predicted later school dropout and/or that school engagement decreased the probability of dropping out.

Research on school engagement refers to truant behavior as the most common specific indicator of engagement (e.g. Markussen, Froseth, Sandberg, Lodding, \& Spord Borgen, 2011; Rumberger \& Ah Lim, 2008). Other studies have focused on truancy, not as an element of school engagement itself, but as an independent factor which is negatively correlated with students' behavioral engagement (Virtanen, Lerkkanen, Poikkeus, \& Kuorelahti, 2014). Linssen and Grewe (2005), furthermore, addressed truancy as the most significant 'European issue'. Truancy is defined as a gradual increase in being absent in school (Stamm, 2007). It usually relates positively to dropping out, i.e. students with a higher truancy rate are more likely to drop out and less likely to graduate (Rumberger \& Ah Lim, 2008). Therefore, irregular school attendance may be seen as one of the first steps toward school dropout (Rosenblum, Goldblatt, \& Moin, 2008). However, the question of the relationship between the two constructs, school engagement and truancy, remains a subject for further empirical analysis.

\subsection{Who Is at Risk of Low School Engagement?}

Addressing the question why students quit school, Lamb (2011) summarized several types of effects on multiple levels of analysis, such as individual student effects, family effects, school effects, peer effects, community effects, and nation effects. Focusing on individual and school-related determinants of students' school engagement, a Swiss study by Makarova and Herzog (2013) suggested that those predictors which are important toschool dropout are also crucial to students' school engagement.

Among students' individual characteristics, studies consistently showed that age is negatively related to school engagement (Blumenfeld et al., 2005; Damian, Stoeber, Negru-Subtirica, \& Băban, 2017; Makarova \& Herzog, 2013). With regard to sex, studies consistently reported that boys are less engaged in school than girls (Audas \& Willms 2001; Blumenfeld et al., 2005; Fredricks et al. 2005; Makarova \& Herzog, 2013; Marks, 2000; Roderick, 2003; Yazzie-Mintz, 2010). In the context of ethnicity, the empirical evidence is heterogeneous. Some studies reported less engagement among minority students (Audas \& Willms 2001; Bingham \& Okagaki, 2012), whereas others reported no differences or even more engagement among minority students, depending on their ethnicity (Johnson, Crosnoe, \& Elder, 2001; Makarova \& Herzog, 2013; Shernoff \& Schmidt, 2008; Uekawa, Borman, \& Lee, 2007). Finally, with respect to family background, empirical evidence showed that a higher socio-economic status was associated with greater school engagement (Marks, 2000; Yazzie-Mintz, 2010).

Among school-related factors, students' attitudes to the formal aspects of school, their academic achievement and their relationships with peers and adults at school were found to impact students' school engagement (Audas \& Willms, 2001; Furrer \& Skinner, 2003; Göbel, Makarova, \& Filsecker, 2016; Lamb, 2011; Makarova \& Herzog, 2013; Roderick, 2003; Rumberger, 2001, 2004). In a number of studies the quality of students' relationships in school has been recognized as one of the prominent factors influencing students' school engagement (e.g. Birch \& Ladd, 1997; De Laet et al., 2015; Makarova \& Herzog, 2013; Wang \& Eccles, 2013), and school-based supportive relationships were shown to have 'a key influence on academic engagement' (Suárez-Orozco, Pimentel, \& Martin, 2009, p. 730).

Even if it seems clear that the quality of relationships with peers and teachers are important with regard to engagement, truancy, and dropout, there is only mixed evidence on the detailed nature of the associations 
between these constructs. Some studies have stressed that both types of relationships-with teachers and with peers-are equally important and that each type is a necessary, but not a sufficient condition for school engagement (e.g. Rosenfeld, Richman, \& Bowen, 2000).

Other studies viewed peer relationships and the student-teacher relationship as correlated aspects, but two unique predictors of school engagement (e.g. De Laet et al., 2015; Furrer \& Skinner, 2003). For example, Virtanen et al. (2014) reported that students' perception of teacher support was positively associated with engagement, but that perceived peer support and school engagement were not associated. Wang and Eccles (2013) showed that peer social support predicted adolescents' school identification less strongly than teachers' social support. In contrast, Ladd, Birch and Buhs (1999) found that peer acceptance had the greatest impact on school participation. Finally, some studies showed an effect of one of the relationship sources on the other. For example, Hughes and Kwok (2006) reported a positive effect of teacher support on subsequent peer acceptance, which was fully mediated by school engagement.

With respect to the student-teacher relationship the most recent meta-analysis of 189 studies by Roorda, Jak, Zee, Oort, \& Koomen (2017), in line with previous single studies which were not analyzed by the meta-analysis, reported a positive association between a positive student-teacher relationship or teacher support and school engagement (Battistich, Solomon, Watson, \& Schaps, 1997; Cadima, Doumen, Verschueren, \& Buyse, 2015; Garcia-Reid, Peterson, \& Reid, 2015; McNeely \& Falci, 2004; Papadopoulou \& Gregoriadis, 2017). In addition, a negative association between a conflictual student-teacher relationship and school engagement were confirmed in previous research (Cadima et al., 2015; Papadopoulou \& Gregoriadis, 2017). Furthermore, peer relationships and the student-teacher relationship were proven to be important factors not only in predicting school engagement, but also truancy, and school dropout. According to a longitudinal study by De Laet et al. (2015) not only was peer acceptance in Grade 4 associated with a less steep decline in behavioral engagement later on, but also had a significant positive effect on behavioral engagement in Grade 6. Similarly, some studies have not only shown an immediate effect of the student-teacher relationship on school engagement, but also a long term effect of that relationship on school engagement (Cadima et al., 2015; Da Laet et al., 2015; Doumen, Koomen, Buyse, Wouters, \& Verschueren, 2012; Hughes \& Kwok, 2006).

Few studies analyzed the associations between relationships in school, school engagement, and truancy. A study by Rosenfeld et al. (2000) showed that although the consequences of teacher support were relevant for school engagement as well as for truancy, they appeared to be greatest for affective variables like engagement and less important for school behavior like attendance. Finally, a study by Virtanen et al. (2014) demonstrated that school engagement mediated the negative association between teacher support and truancy. Woolley and Bowen (2007) found that, among other indicators, the quality of the student-teacher relationship played the mediating role in the negative influence of contextual risks on school engagement. These findings underline the important role of school engagement in connection with relationships at school and students' truancy.

Overall, we can state that research findings on the relation between school engagement and school dropout are consistent, suggesting that low school engagement can lead to eventual school dropout and that students' individual characteristics can be positively or negatively related to their school engagement. Moreover, research on school engagement suggests that the quality of student-teacher and student-student relationships in school are among those factors which have a strong and lasting impact on students' school engagement. Although studies on the student-teacher relationship differ in operationalizing the relationship construct, they commonly show that experiences of closeness, support and involvement in student-teacher relationships have a positive impact on students' school engagement. Similarly, students' experiences of peer acceptance and social integration in the school context have a positive impact on students' school attendance.

\section{Method}

Based on the state of current research, our study aimed to advance knowledge on students' school engagement by establishing a more comprehensive understanding of school engagement and truancy and by focusing on the meaning of students' individual characteristics and on their relationships with teachers and classmates. The following questions guide our empirical analysis:

a) Which students are at risk of low school engagement and high truancy?

b) How do relationships with peers and teachers impact students' engagement and their truant behavior?

c) Does low school engagement lead to more truancy?

The data for our analysis originated from the Swiss cross-sectional study Latent school absenteeism, which was conducted as a part of an international collaborative research project. This research project was aimed at 
detecting the school-related and individual factors that determine school engagement and school dropout in various European countries (Author et al., 2014).

\subsection{Sample}

In all, 220 students from seven public schools in a German speaking part of Switzerland participated in the survey ( $47.9 \%$ female and $52.1 \%$ male). The students were between the seventh and ninth grade in 13 different classes, which had a high proportion of students with a migration background (on average $71.5 \%$ ). The study distinguished between three categories of migration background. The category immigrant $(51.9 \%)$ included youth of whom both parents were born abroad. Youth of whom only one parent was born abroad constituted the category binational (19.6\%). Finally, students whose parents were both born in Switzerland comprised the category, native youth (28.5\%). On average, the students were 14.7 years old.

\subsection{Measures}

The participants completed a questionnaire during class time and were instructed and supervised by trained research assistants. Mostly, the teachers left the classroom. In some situations they asked to stay with their class for reasons of classroom dynamics. However, they did not interfere in the conducting of the survey and the responsibility rested with the research assistants. The completion time was set to one lesson and announced to the students. All of the students completed the questionnaire in 37 to 55 minutes. For students who finished early, every teacher had assigned a task in advance of the survey that was to be completed individually and in silence afterwards. After each survey the research assistants completed a report in which they noted on one hand their evaluation of the class (concentration, talking, chuckling, etc.) and, on the other, their overall evaluation of the survey situation. Seven classes were rated as concentrated or highly concentrated. Five classes were rated as concentrated, but a little bit noisy, and one class was rated as difficult to handle. In nine of the 13 classes the overall evaluation was regarded as very easy or easy. The remaining four classes were regarded as average.

School Engagement was operationalized as combined behavioral, cognitive and emotional engagement (Fredricks et al., 2005 modified; 13 items, Likert scale from 1 to 4 (on occasion, some of the time, most of the time, all of the time), Cronbach's $\alpha=.80$ ). For example, one item of the behavioral dimension was: 'I follow the rules of my school'.

Truancy was operationalized as the frequency of truancy within the last school year (Sälzer, 2010; seven items, Likert scale from 1 to 3 (never, from time to time, more than 5 times), Cronbach's $\alpha=.88$ ) and measured with an item like: 'Did you skip school directly before or after school holidays during the last school year?'.

The scale student-teacher relationship (Schönbächler, 2008; five items, Likert scale from 1 to 4 (fully disagree, partly disagree, partly agree, fully agree), Cronbach's $\alpha=.89$ ) included items like 'My teacher helps me with problems at school'.

Relationships with peers (Lehmann, Gänsfuss, \& Peek, 1999; seven items, Likert scale from 1 to 4 (fully disagree, partly disagree, partly agree, fully agree), Cronbach's $\alpha=.79$ ) was operationalized as the feeling of being part of the class and school and was measured with items like 'I have really good friends at school'.

The students' individual characteristics were operationalized as age, migration background (three groups: native, binational, immigrant youth) and sex. The socio-economic background was reflected by the family's (ISEI from the mother or the father, depending on which was higher) Highest International Socio-Economic Index of Occupational Status (HISEI), which was derived from the International Socio-Economic Index of Occupational Status (ISEI) (Ganzeboom \& Treiman, 1996).

Finally, the study controlled for students' grades as a mean variable of the following subjects: instructional language (German), mathematics, and foreign language (French).

\section{Results}

In order to answer the research questions, a bivariate-correlations analysis and partial correlation analysis were first conducted to show existing associations between the included variables and constructs. Afterwards, the impact of students' individual characteristics and school-related factors on their engagement in school as well as on their truant behavior was analyzed. Based on these results, a mediation analysis was performed to investigate the connection between student-teacher relationship, engagement, and truancy.

\subsection{Bivariate Correlations Between All Included Variables and Scales}

In Table 1 the inter-correlations between the surveyed variables and scales are presented. The table shows that among students' individual characteristics neither migration background nor sex nor HISEI show a significant correlation with any of the target constructs (truancy, engagement, student-teacher relationship, and relationships 
with peers). Age correlates significantly positively with truancy (Pearson's $r=.24, p \leq .01$ ) and significantly negatively with the student-teacher relationship (Pearson's $r=-.34, p \leq .01$ ). Finally, grades show slightly positive associations with school engagement (Pearson's $\mathrm{r}=.14, \mathrm{p} \leq .05$ ).

All target constructs, except truancy and the relationships with peers, correlate significantly with each other. The correlation between truancy and the student-teacher relationship is negative (Pearson's $r=-.22, p \leq .01$ ). In contrast, school engagement correlates positively with both relationship factors, the student-teacher relationship and relationships with peers. The correlation between engagement and the student-teacher relationship is stronger (Pearson's $\mathrm{r}=.41, \mathrm{p} \leq .01$ ) than that between engagement and relationships with peers (Pearson's $\mathrm{r}=.19, \mathrm{p} \leq .01$ ). Truancy and school engagement show a relatively strong negative correlation (Pearson's $r=-.41, p \leq .01$ ). The student-teacher relationship and relationships with peers correlate moderately positively with each other (Pearson's $\mathrm{r}=.20, \mathrm{p} \leq .01$ ). In sum, the student-teacher relationship seems to be more strongly associated with engagement and truancy than relationships with peers. Furthermore, truancy and school engagement indicate different correlation patterns with students' age and grades, suggesting they are two different constructs.

Table 1. Inter-correlations

\begin{tabular}{|c|c|c|c|c|c|c|c|c|}
\hline Variable & (2) & (3) & (4) & (5) & (6) & (7) & $(8)$ & (9) \\
\hline Truancy (1) & $-.41 * *$ & $-.22 * *$ & -.04 & .07 & -.02 & $.24 * *$ & .07 & -.04 \\
\hline Engagement (2) & & $.41 * *$ & $.19^{* *}$ & $.14^{*}$ & -.08 & -.13 & .11 & -.04 \\
\hline Relationship teacher (3) & & & $.20 * *$ & .13 & .02 & $-.34 * *$ & .02 & .03 \\
\hline Relationships peers (4) & & & & .06 & .10 & -.13 & .10 & -.03 \\
\hline Grades (5) & & & & & $-.14^{*}$ & $-.20 * *$ & -.13 & .11 \\
\hline $\operatorname{Sex}(6)$ & & & & & & $.17 *$ & .03 & -.05 \\
\hline Age (7) & & & & & & & .11 & $-.19 * *$ \\
\hline Migration background (8) & & & & & & & & $-.31 * *$ \\
\hline HISEI (9) & & & & & & & & \\
\hline
\end{tabular}

Note. ${ }^{*} \mathrm{p} \leq .05,{ }^{*} \mathrm{p} \leq .01,{ }^{* * *} \mathrm{p} \leq .001 ; \mathrm{N}=193-220$.

\subsection{Zero-Order and Partial Correlation}

Due to the significant results of the correlation analysis, partial correlations were run to determine the relationships between our target constructs engagement, truancy, student-teacher relationship, and relationships with peers (see Table 2).

The results indicate that when sex, migration background, HISEI, age, grades, relationships with peers, and engagement are controlled for, there is no significant correlation between truancy and the student-teacher relationship. In line with this, when sex, migration background, HISEI, age, grades, relationship with teacher and engagement are controlled for, there is no significant association between truancy and relationships with peers. In contrast, students' school engagement shows a moderate to relatively strong positive association with the student-teacher relationship (Pearson's $\mathrm{r}=.34, \mathrm{p} \leq .001$; control variables: sex, migration background, HISEI, age, grades, relationships peers, and truancy) as well as a weaker, but significant, association with relationships with peers (Pearson's $r=.17, \mathrm{p} \leq .05$; control variables: sex, migration background, HISEI, age, grades, relationship teacher, and truancy). The results for engagement and truancy show, even after controlling for sex, migration background, HISEI, age, grades, relationships with peers, and relationship with teacher, a moderate to strong negative correlation which is statistically significant (Pearson's $\mathrm{r}=-.42, \mathrm{p} \leq .001$ ). These results support the assumption that the quality of relationships is crucial to school engagement, but at the same time indicate that there are other factors that affect the connection between truancy and relationships in school. Finally, the student-teacher relationship and relationships with peers show no significant correlation after sex, migration background, HISEI, age, grades, engagement and truancy are controlled for. 
Table 2. Zero-order and partial correlation between the target constructs

\begin{tabular}{llll}
\hline Variable & $(1)$ & $(2)$ & $(3)$ \\
\hline Truancy (1) & & & \\
Engagement (2) & & & \\
Engagement (2) & $-.41^{* * *}$ & & \\
Relationship teacher (3) $^{\mathrm{a}}$ & $-.42^{* * *}$ & $.43^{* * *}$ & \\
Relationship teacher (3) $^{\mathrm{a}}$ & $-.22^{* *}$ & $.35^{* * *}$ & $.21^{* *}$ \\
Relationships peers (4) $^{\mathrm{a}}$ & .00 & $.22^{* *}$ & .10 \\
Relationships peers (4) & -.02 & $.17^{*}$ & \\
\hline
\end{tabular}

Note. ${ }^{*} \mathrm{p} \leq .05,{ }^{* *} \mathrm{p} \leq .01,{ }^{* * *} \mathrm{p} \leq .001 ; \mathrm{N}=183 ;{ }^{\mathrm{a}}$ Control variable (none).

\subsection{Students' Individual Characteristics and School-Related Factors as Predictors of Their Engagement in School}

In order to analyze the influence of students' individual characteristics and school-related factors on their engagement in school, a generalized linear model was applied. The covariates relationships with peers, student-teacher relationship and grades were included as school-related factors. The categorical predictors sex and migration background as well as the covariates HISEI and age were entered as students' individual characteristics. The model included 183 cases (83.2\%). The fitted model is significant compared to the intercept-only model $\left(\right.$ Likelihood Ratio $\left.\chi^{2}(8,183)=51.76, \mathrm{p} \leq .001\right)$. The goodness-of-fit test showed an acceptable fit (Deviance Ratio=.829). The test of model effects indicates that only one school factor (student-teacher relationship) and one individual characteristic (migration background) are significant predictors of students' engagement in school. The factor relationships with peers is not a significant predictor of school engagement (see Table 3).

Table 3. Test of model effect—Engagement

\begin{tabular}{llll}
\hline Parameter & Wald Chi-square & $d f$ & Sig. \\
\hline (Intercept) & .00 & 1 & .991 \\
Relationship teacher & 29.81 & 1 & .000 \\
Relationships peers & 3.15 & 1 & .076 \\
Grades & 1.19 & 1 & .275 \\
Sex & .76 & 1 & .384 \\
Age & .57 & 1 & .449 \\
Migration background & 6.12 & 2 & .047 \\
HISEI & .06 & 1 & .813 \\
\hline
\end{tabular}

Note. Dependent variable: Engagement (z-score: $\mathrm{M}=.04, \mathrm{SD}=1.03)$; Model (Intercept): Sex, migration background, HISEI (z-score: M=43.14, $\mathrm{SD}=13.49$ ), age ( $\mathrm{z}$-score: $\mathrm{M}=-.07, \mathrm{SD}=.97)$, grades ( $\mathrm{z}$-score: $\mathrm{M}=.04, \mathrm{SD}=.95)$, relationships peers ( $\mathrm{z}$-score: $\mathrm{M}=.01, \mathrm{SD}=1.00$ ), relationship teacher ( $\mathrm{z}$-score: $\mathrm{M}=.07, \mathrm{SD}=1.03$ ).

The regression coefficient of the model shows that a positive student-teacher relationship is associated with greater engagement in school. The effect size, based on odds ratios $\operatorname{Exp}(\beta)$, indicates that students' school engagement is higher by a factor of 1.51 for students with a better student-teacher relationship (see Table 4). Additionally, binational students are less engaged in school than immigrant students. The effect size shows lower engagement for binational students by a factor of .63. The post-hoc pairwise comparison for every pair of the factor migration background shows a significant difference only between immigrant and binational students (Mean difference: .47, $\mathrm{SE}=.19, \mathrm{p} \leq .05)$. 
Table 4. Students' individual characteristics and school-related factors as predictors of school engagement

\begin{tabular}{lllllll}
\hline Parameter & $\beta$ & $S E$ & Wald Chi-square & $d f$ & Sig. & $\operatorname{Exp}(\beta)$ \\
\hline (Intercept) & .14 & .20 & .50 & 1 & .479 & 1.16 \\
Relationship teacher & .41 & .08 & 29.81 & 1 & .000 & 1.51 \\
Relationships peers & .13 & .08 & 3.15 & 1 & .076 & 1.14 \\
Grades & .09 & .08 & 1.19 & 1 & .275 & 1.10 \\
Male & .12 & .13 & .76 & 1 & .384 & 1.12 \\
Female & $0^{\mathrm{a}}$ & & & & & 1 \\
Age & .05 & .07 & .57 & 1 & .449 & 1.06 \\
Native & -.15 & .15 & .94 & 1 & .333 & .86 \\
Binational & -.47 & .19 & 6.10 & 1 & .014 & .63 \\
Immigrant & $0^{\mathrm{a}}$ & & & & & 1 \\
HISEI & -.00 & .00 & .06 & 1 & .810 & 1.00 \\
\hline
\end{tabular}

Note. ${ }^{\text {a }}$ Set to 0 because this parameter is redundant.

\subsection{Students' Individual Characteristics and School-Related Factors as Predictors of Their Truant Behavior}

A second generalized linear model was applied to analyze the influence of students' individual characteristics and school-related factors on their truant behavior. Again, the covariates student-teacher relationship, relationships with peers, and grades were included as school-related factors and the categorical predictors sex and migration background as well as the covariates HISEI and age were entered as students' individual characteristics. The model included 184 cases $(83.6 \%)$. The fitted model is significant compared to the intercept-only model (Likelihood Ratio $\left.\chi^{2}(8,183)=26.18, \mathrm{p} \leq .001\right)$. The goodness-of-fit test shows an acceptable fit (Deviance Ratio=.973). The test of model effects shows that among students' individual characteristics only age is a significant predictor of students' truant behavior. Migration background and the student-teacher relationship are not significant, but show a tendency to be so (see Table 5).

Table 5. Test of model effect-Truant behavior

\begin{tabular}{llll}
\hline Parameter & Wald Chi-square & $d f$ & Sig. \\
\hline (Intercept) & .07 & 1 & .792 \\
Relationship teacher & 3.18 & 1 & .074 \\
Relationships peers & .10 & 1 & .747 \\
Grades & 2.25 & 1 & .134 \\
Sex & 1.41 & 1 & .235 \\
Age & 12.26 & 1 & .000 \\
Migration background & 5.14 & 2 & .077 \\
HISEI & .07 & 1 & .795 \\
\hline
\end{tabular}

Note. Dependent variable: Truancy ( $\mathrm{z}$-score: $\mathrm{M}=-.02, \mathrm{SD}=1.04)$; Model (Intercept): Sex, migration background, HISEI (z-score: $\mathrm{M}=43.18$, $\mathrm{SD}=13.46$ ), age ( $\mathrm{z}$-score: $\mathrm{M}=-.06, \mathrm{SD}=.97$ ), grades ( $\mathrm{z}$-score: $\mathrm{M}=.03, \mathrm{SD}=.95$ ), relationships peers ( $\mathrm{z}$-score: $\mathrm{M}=.01$, $\mathrm{SD}=1.00$ ), relationship teacher ( $\mathrm{z}$-score: $\mathrm{M}=.06, \mathrm{SD}=1.01$ ).

The regression coefficient of the model indicates that older students show more truant behavior than younger students. The effect size shows that students' truant behavior is higher by a factor of 1.28 for students who were older (see Table 6). 
Table 6. Students' individual characteristics and school-related factors as predictors of students' truant behavior

\begin{tabular}{lllllll}
\hline Parameter & $\beta$ & SE & Wald Chi-square & $d f$ & Sig. & Exp $(\beta)$ \\
\hline (Intercept) & -.06 & .18 & .10 & 1 & .757 & .95 \\
Relationship teacher & -.19 & .10 & 3.18 & 1 & .074 & .83 \\
Relationships peers & .03 & .10 & .10 & 1 & .747 & 1.03 \\
Grades & .15 & .10 & 2.25 & 1 & .134 & 1.16 \\
Male & .17 & .14 & 1.41 & 1 & .235 & 1.18 \\
Female & $0^{\mathrm{a}}$ & & & & & 1 \\
Age & .24 & .07 & 12.26 & 1 & .000 & 1.28 \\
Native & -.28 & .16 & 3.13 & 1 & .077 & .76 \\
Binational & .04 & .23 & .03 & 1 & .853 & 1.04 \\
Immigrant & $0^{\mathrm{a}}$ & & & & & .795 \\
HISEI & .00 & .00 & .07 & 1 & .795 & 1.00 \\
\hline
\end{tabular}

Note. ${ }^{\text {a }}$ Set to 0 because this parameter is redundant.

\subsection{Mediation}

Because the results underline the importance of the student-teacher relationship in connection with truancy and especially students' school engagement, a simple mediation analysis was conducted to analyze the relationship between the student-teacher relationship, engagement, and truancy. Relationships with peers were entered in the model as a covariate. Using ordinary least squares path analysis, the student-teacher relationship was shown to indirectly influence the occurrence of truancy. As presented in Figure 1 and Table 7, students with a positive student-teacher relationship show more engagement in school $(\mathrm{a}=.42)$ and more engaged students indicate less truant behavior $(b=-.45)$. A bias-corrected bootstrap confidence interval or the indirect effect $(a b=-.18)$ based on $10^{\prime} 000$ bootstrap samples was entirely under zero $(-.28$ to -.09$)$. There is no evidence that the student-teacher relationship influence the occurrence of truancy directly $\left(c^{\prime}=.00\right)$, which means that the relationship association between the student-teacher relationship and truancy is fully mediated by students' school engagement $(a b=-.18)$.

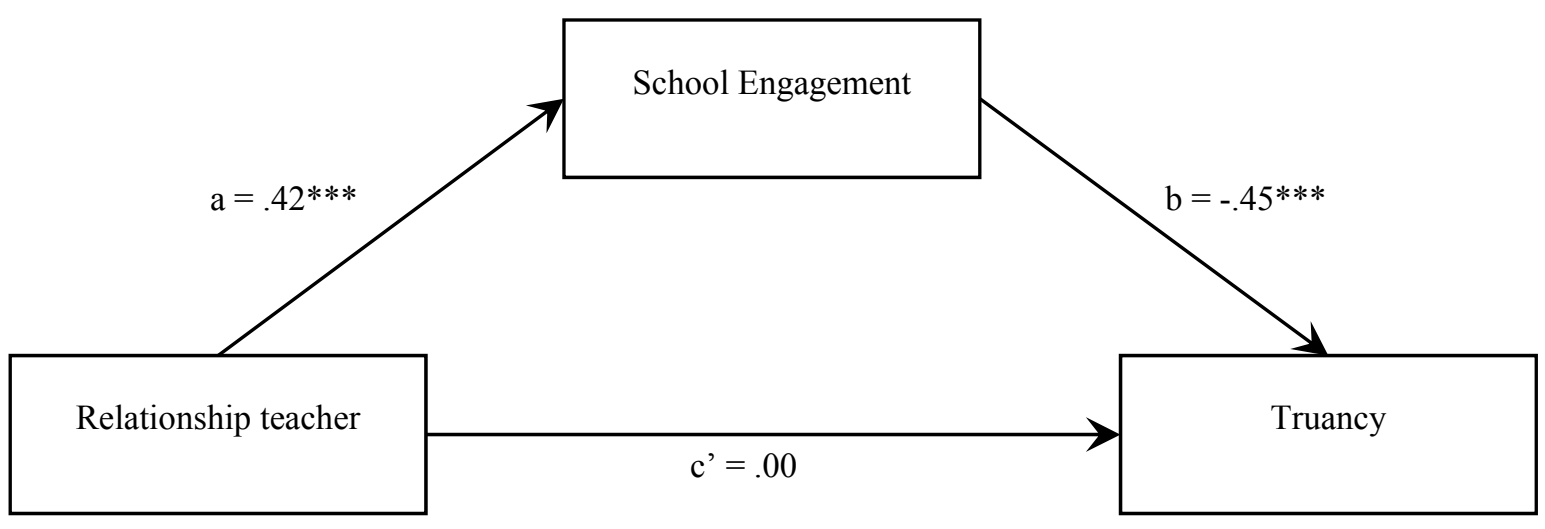

Figure 1. The mediation effect of students' school engagement on the relation between the student-teacher relationship and truancy

Note. $* * * \leq .001$. 
Table 7. The mediation model

\begin{tabular}{|c|c|c|c|c|c|c|c|c|}
\hline & & \multicolumn{4}{|c|}{ Engagement } & \multicolumn{3}{|c|}{ Truancy } \\
\hline \multicolumn{2}{|l|}{ Antecedents } & Coeff. & SE & $\mathrm{p}$ & & Coeff. & SE & $\mathrm{p}$ \\
\hline Relationship teacher & $\mathrm{a}$ & .42 & .08 & $<.001$ & $c^{\prime}$ & .00 & .10 & 991 \\
\hline Engagement & & - & - & - & $\mathrm{b}$ & -.45 & .10 & $<.001$ \\
\hline \multirow[t]{3}{*}{ Constant } & $\mathrm{i}_{1}$ & .08 & .39 & .848 & $\mathrm{i}_{2}$ & -.07 & .34 & .838 \\
\hline & & \multicolumn{4}{|c|}{$\mathrm{R}^{2}=.223$} & \multicolumn{3}{|c|}{$\mathrm{R}^{2}=.276$} \\
\hline & & \multicolumn{4}{|c|}{$\mathrm{F}(7,175)=5.90, \mathrm{p} \leq .001$} & \multicolumn{3}{|c|}{$\mathrm{F}(8,174)=3.65, \mathrm{p} \leq .001$} \\
\hline
\end{tabular}

Note. Control Variables: Migration background, sex, HISEI, age, grades, relationships peers.

\section{Discussion}

The aim of this study was to advance knowledge on students' school engagement by investigating more comprehensively the relationship between school engagement and truancy and by focusing on the effect of students' individual characteristics and their relationships with teachers and classmates.

Concerning the question as to which students are at risk of low school engagement, our study shows that school-related factors in particular seem to be crucial. This finding stands in contrast with recent research emphasizing individual characteristics like age, sex, and family background as determining (e. g. Blumenfeld et al., 2005; Marks, 2000; Yazzie-Mintz, 2010). In our study none of the students' individual characteristics was associated with an extension of students' school engagement except for binational migration background. Binational students show less engagement than immigrant students but no differences compared to native students. As none of the previous studies on school engagement operationalized this particular category of students' migration background, we cannot directly link this finding to previous research. However, our study supports previous studies' notion that there is a complex relationship between students' origin and their school engagement and other academic outcomes (Shernoff \& Schmidt, 2008) which needs to be further analyzed.

On the other hand, our study supports various findings that underline the importance of school-related factors such as academic achievement and relationships at school (e. g. Audas \& Willms, 2001; Makarova \& Herzog, 2013; Rumberger, 2001, 2004) by indicating a positive association between students' school engagement and grades as well as relationships with peers and the student-teacher relationship. In addition, our findings show that only the student-teacher relationship turned out to be a significant predictor of students' school engagement. This finding is in line with the meta-analysis of Roorda et al. (2017) and previous single studies, which reported a positive association between a positive student-teacher relationship or teacher support and school engagement (e. g. Battistich et al., 1997; Cadima et al., 2015). Therefore, we sum up that, especially binational students and students with a poor student-teacher relationship are at risk of low school engagement.

Concerning the question which students are at risk of high truancy, the results show that different factors seem to be important for truancy than those for school engagement. Truant behavior correlates positively with age as a student individual characteristic and negatively with the student-teacher relationship. According to the generalized linear model, only students' increasing age leads to more truancy, which means that older students are more at risk of truancy than younger ones. These results are in line with previous research, which also show a negative relationship between age and school engagement (Blumenfeld et al., 2005; Damian et al. 2017; Makarova \& Herzog, 2013).

Some of the results presented above are also important for answering the second question on how relationships with peers and the teachers impact students' school engagement and their truant behavior. In our study, the student-teacher relationship is revealed to be the most important factor in connection with school engagement. Even if there is a correlation between school engagement and relationships with peers, this correlation disappeared after further analyses controlling for student-teacher relationship, grades, sex, age, migration background, and family background. These results confirm the findings of other studies reporting that peer relationships and the student-teacher relationship are correlated, but are two unique aspects of students' social integration at school (e.g. De Laet et al., 2015; Furrer \& Skinner, 2003; Virtanen et al., 2014). In contrast, the student-teacher relationship and relationships with peers seem to be less important for students' truant behavior and neither of them leads to a lower or higher truancy rate. In accordance to this, our study supports the notion that school engagement and truancy are strongly correlated and that both are highly important with regard to school dropout, but need to be distinguished (e. g. Virtanen et al., 2014). These results are similar to those of Rosenfeld et al. (2000), who showed that the consequences of teacher support appeared to be greatest for affective variables like engagement and less important for school behavior like attendance. 
To summarize, it can be stated that on one hand the student-teacher relationship plays a major role in the topic of engagement, truancy, and dropout. On the other, school engagement and truancy share a strong bond, but need to be analyzed as distinctive constructs. Based on this, the question of whether low school engagement leads to more truancy was examined. The mediation analysis shows that the student-teacher relationship does not have a direct effect on truancy, but on school engagement. Furthermore, engagement has a strong direct effect on truancy, which means that an increase in school engagement leads to a decrease in the truancy rate and that low school engagement leads to more truancy. Finally, the student-teacher relationship has an indirect effect on truancy, which is fully mediated by school engagement. This signifies that a positive student-teacher relationship only leads to a decrease in the truancy rate in connection with school engagement. These results support the finding of Virtanen et al. (2014), who also detected that school engagement mediated the negative association between teacher support and truancy.

\section{Conclusion and Limitations}

Our results have important implications for the prevention of school dropout. In particular, they show that teachers can promote their students' school engagement through building and maintaining positive relationships in the classroom. Moreover, by establishing caring and supportive relationships with students and by increasing their school engagement, teachers can prevent students' truant behavior and possibly even their dropping out of school. Taking into account that in our study youth of binational heritage indicated low school engagement and in other studies immigrant youth were associated with a higher risk of dropping out of school, it can be stated that teachers who establish positive relationships with their students can decisively support the school adjustment of students with a migration background. In order to promote educational equality, it is imperative to consider the maintenance of a positive student-teacher relationship as a key competence of pedagogical praxis.

Our study also has some limitations. Firstly, it employed a cross-sectional design and therefore cannot describe the developmental and causal relationships between the constructs included. Hence, a longitudinal study would be needed to analyze the relationship between school engagement, truancy, and school dropout over the long term. Secondly, our analyses are based on the students' self-reported engagement in a standardized questionnaire. Further research should apply a mixed methods design and a combination of assessment instruments, including teacher ratings, interviews, and observation in order to assess social dynamics in classrooms for a more comprehensive picture of school engagement and truancy. Thirdly, our study focused on individual characteristics and social relationships in classrooms. Further research should include additional levels of analysis such as family, friends, school environment, and neighborhood. To achieve this, it would be necessary, to include teachers, parents, and friends, so they would be able to contribute further information about the processes connected to school engagement and truancy. Finally, our results are based on a student sample from one country; more research is needed in other countries in order to gain an international perspective and thus a more comprehensive understanding of school engagement, truancy, and school dropout.

\section{References}

Alexander, K. L., Entwisle, D. R., \& Horsey, C. S. (1997). From first grade forward: Early foundations of high school dropout. Sociology of Education, 70, 87-107. https://doi.org/10.2307/2673158

Appleton, J. J., Christenson, S. L., \& Furlong, M. J. (2008). Student engagement with school: Critical conceptual and methodological issues of the construct. Psychology in the Schools, 45(5), 369-386. https://doi.org/10.1002/pits.20303

Audas, R., \& Willms, J. D. (2001). Engagement and dropping out of school: A life-course perspective. Hull: Applied Research Branch, Human Resources Development Canada.

Battistich, V., Solomon, D., Watson, M., \& Schaps, E. (1997). Caring school communities. Educational Psychologist, 32(3), 137-151. https://doi.org/10.1207/s15326985ep3203_1

Bingham, G. E., \& Okagaki, L. (2012). Ethnicity and student engagement. In A. L. Reschly \& C. Wylie (Eds.), Handbook of research on student engagement (pp. 65-95). Springer: Boston. https://doi.org/10.1007/978-1-4614-2018-7_4

Birch, S. H., \& Ladd, G. W. (1997). The teacher-child relationship and children's early school adjustment. Journal of School Psychology, 35(1), 61-79. https://doi.org/10.1016/S0022-4405(96)00029-5

Blumenfeld, P., Modell, J., Bartko, W. T., Secada, W. G., Fredricks, J. A., Friedel, J., \& Paris, A. (2005). School engagement of inner-city students during middle childhood. In C. R. Cooper, C. T. Garcia Coll, W. T. Bartko, H. Davis, \& C. Chatman (Eds.), Developmental pathways through middle childhood. Rethinking contexts and diversity as resources (pp. 145-170). Mahwah: Lawrence Erlbaum Associates. 
Cadima, J., Doumen, S., Verschueren, K., \& Buyse, E. (2015). Child engagement in the transition to school: contributions of self-regulation, teacher-child relationships and classroom climate. Early Childhood Research Quarterly, 32, 1-12. https://doi.org/10.1016/j.ecresq.2015.01.008

Damian, L. E., Stoeber, J., Negru-Subtirica, O., \& Băban, A. (2017). Perfectionism and school engagement: A three-wave longitudinal study. Personality and Individual Differences, 105, 179-184. https://doi.org/10.1016/j.paid.2016.09.044

De Laet, S., Colpin, H., Vervoort, E., Doumen, S., Van Leeuwen, K., Goossens, L., \& Verschueren, K. (2015). Developmental trajectories of children's behavioral engagement in late elementary school: Both teachers and peers matter. Developmental Psychology, 51(9), 1292-1306. https://doi.org/10.1037/a0039478

Doumen, S., Koomen, H. M., Buyse, E., Wouters, S., \& Verschueren, K. (2012). Teacher and observer views on student-teacher relationships: Convergence across kindergarten and relations with student engagement. Journal of School Psychology, 50(1), 61-76. https://doi.org/10.1016/j.jsp.2011.08.004

European Commission (2013). Reducing early school leaving. Key Messages and policy support. Final report of the Thematic Working Group on Early School Leaving. Retrieved from http://ec.europa.eu/education/policy/strategic-framework/doc/esl-group-report_en.pdf [04.07.2018]

Fall, A. M., \& Roberts, G. (2012). High school dropouts: Interactions between social context, self-perceptions, school engagement, and student dropout. Journal of Adolescence, 35(4), 787-798. https://doi.org/10.1016/j.adolescence.2011.11.004

Federal Statistical Office (FSO) (2018). Medienmitteilung. 90.9\% der jungen Erwachsenen mit einem Abschluss der Sekundarstufe II bis zum 25. Altersjahr [Press release. 90.9\% of young people with an upper secondary level qualification by the age of 25]. Neuenburg: Federal Statistical Office.

Fredricks, J. A., Blumenfeld, P. C., \& Paris, A. H. (2004). School engagement: Potential of the concept, state of the evidence. Review of educational research, 74(1), 59-109. https://doi.org/10.3102/00346543074001059

Fredricks, J. A., Blumenfeld, P., Friedel, J., \& Paris, A. (2005). School engagement. In K. A. Moore \& L. Lippman (Eds.), What do children need to flourish?: Conceptualizing and measuring indicators of positive development (pp. 305-321). New York, NY: Springer Science and Business Media. https://doi.org/10.1007/0-387-23823-9_19

Furlong, M. J., Whipple, A. D., Jean, G. S., Simental, J., Soliz, A., \& Punthuna, S. (2003). Multiple contexts of school engagement: Moving toward a unifying framework for educational research and practice. The California School Psychologist, 8(1), 99-113. https://doi.org/10.1007/BF03340899

Furrer, C., \& Skinner, E. (2003). Sense of relatedness as a factor in children's academic engagement and $\begin{array}{lllll}\text { performance. Journal of Educational } & \text { Psychology, } & \text { 95(1), } & \text { 148-162. }\end{array}$ https://doi.org/10.1037/0022-0663.95.1.148

Ganzeboom, H. B. G., \& Treiman, D. J. (1996). Internationally Comparable Measures of Occupational Status for the 1988 International Standard Classification of Occupations. Social Science Research, 25, 201-239. https://doi.org/10.1006/ssre.1996.0010

Garcia-Reid, P., Peterson, C. H., \& Reid, R. J. (2015). Parent and teacher support among Latino immigrant youth: Effects on school engagement and school trouble avoidance. Education and Urban Society, 47(3), 328-343. https://doi.org/10.1177/0013124513495278

Göbel, K., Makarova, E., \& Filsecker, M. (2016). Instructional quality and classroom climate as predictors of school engagement: A Swiss-German cross-cultural explorative study. Paper presented at the $23^{\text {th }}$ International Congress of the International Association for Cross-Cultural Psychology (IACCP). Nagoya, July 30 - August 3.

Hascher, T., \& Hadjar, A. (2018). School alienation-Theoretical approaches and educational research. Educational Research, 60(2), 171-188. https://doi.org/10.1080/00131881.2018.1443021

Henry, K. L., Knight, K. E., \& Thornberry, T. P. (2012). School disengagement as a predictor of dropout, delinquency, and problem substance use during adolescence and early adulthood. Journal of youth and adolescence, 4l(2), 156-166. https://doi.org/10.1007/s10964-011-9665-3

Hughes, J. N., \& Kwok, O. (2006). Classroom engagement mediates the effect of teacher-student support on elementary students' peer acceptance: A prospective analysis. Journal of School Psychology, 43, 465-480. https://doi.org/10.1016/j.jsp.2005.10.001 
Jimerson, S. R., Campos, E., \& Greif, J. L. (2003). Toward an understanding of definitions and measures of school engagement and related terms. The California School Psychologist, 8(1), 7-27. https://doi.org/10.1007/BF03340893

Johnson, M. K., Crosnoe, R., \& Elder, G. H. (2001). Students' attachment and academic engagement: The role of race and ethnicity. Sociology of Education, 74, 318-340. https://doi.org/10.2307/2673138

Ladd, G. W., Birch, S. H., \& Buhs, E. S. (1999). Children's social and scholastic lives in kindergarten: Related spheres of influence?. Child Development, 70(6), 1373-1400. https://doi.org/10.1111/1467-8624.00101

Lamb, S. (2011). School Dropout and Inequality. In S. Lamb, E. Markussen, R. Teese, N. Sandberg, \& J. Polesel (Eds.), School Dropout and Completion. International Comparative studies in Theory and Policy (pp. 369-390). New York: Springer. https://doi.org/10.1007/978-90-481-9763-7_21

Lamb, S., \& Markussen, E. (2011). School Dropout and Completion: An International Perspective. In S. Lamb, E. Markussen, R. Teese, N. Sandberg, \& J. Polesel (Eds.), School Dropout and Completion. International Comparative studies in Theory and Policy (pp. 1-18). New York: Springer. https://doi.org/10.1007/978-90-481-9763-7

Lehmann, R. H., Gänsfuss, R., \& Peek, R. (1999). Aspekte der Lernausgangslage von Schülerinnen und Schülern der fünften Klassen an Hamburger Schulen. Bericht über die Untersuchung im September 1996 [Aspects of the learning capabilities of students of the fifth grade at a school in Hamburg. Report about the study in September 1996]. Hamburg: Department of Education and Sport.

Linssen, R., \& Grewe, N. (2005). Absenteeism as a European Issue. In N. Grewe (Ed.), Absenteeism in European Schools (pp. 7-11). Münster: LIT-Verlag.

Makarova, E., \& Herzog, W. (2013). Hidden school dropout among immigrant students: a cross-sectional study. Intercultural Education, 24(6), 559-572. https://doi.org/10.1080/14675986.2013.867603

Marks, H. M. (2000). Student engagement in instructional activity: Patterns in the elementary, middle, and high school years. American Educational Research Journal, 37(1), 153-184. https://doi.org/10.3102/00028312037001153

Markussen, E., Froseth, M. W., Sandberg, N., Lodding, B., \& Spord Borgen, J. (2011). Early Leaving, Non-Completion and Completion in Upper Secondary Education in Norway. In S. Lamb, E. Markussen, R. Teese, N. Sandberg, \& J. Polesel (Eds.), School Dropout and Completion. International Comparative studies in Theory and Policy (pp. 253-271). New York: Springer. https://doi.org/10.1007/978-90-481-9763-7_14

McNeely, C., \& Falci, C. (2004). School connectedness and the transition into and out of health-risk behavior among adolescents: A comparison of social belonging and teacher support. Journal of School Health, 74(7), 284-292. https://doi.org/10.1111/j.1746-1561.2004.tb08285.x

Morinaj, J., Scharf, J., Grecu, A., Hadjar, A., Hascher, T., \& Marcin, K. (2017). School Alienation: A Construct Validation Study. Frontline Learning Research, 5(2), 36-59. https://doi.org/10.14786/flr.v5i2.298

Newmann, F. M., Wehlage, G. G., \& Lamborn, S. D. (1992). The Significance and Sources of Student Engagement. In F. M. Newmann (Ed.), Student Engagement and Achievement in American Secondary Schools (pp. 11-39). New York: Teachers College Press.

OECD (2012). Equity and Quality in Education: Supporting Disadvantaged Students and Schools. OECD Publishing.

Papadopoulou, E., \& Gregoriadis, A. (2017). Young children's perceptions of the quality of teacher-child interactions and school engagement in Greek kindergartens. Journal of Early Childhood Research, 15(3), 323-335. https://doi.org/10.1177/1476718X16656212

Reschly, A. L., \& Christenson, S. L. (2012). Jingle, jangle, and conceptual haziness: Evolution and future directions of the engagement construct. In S. L. Christenson, A. L. Reschly, \& C. Wylie (Eds.), Handbook of research on student engagement (pp. 3-19). Springer: Boston, MA. https://doi.org/10.1007/978-1-4614-2018-7_1

Roderick, M. (2003). What's happening to the boys? Early high school experiences and school outcomes among African American male adolescents in Chicago. Urban Education, 38(5), 538-607. https://doi.org/10.1177/0042085903256221

Roorda, D. L., Jak, S., Zee, M., Oort, F. J., \& Koomen, H. M. (2017). Affective Teacher-Student Relationships 
and Students' Engagement and Achievement: A Meta-Analytic Update and Test of the Mediating Role of Engagement. School Psychology Review, 46(3), 239-261. https://doi.org/10.17105/SPR-2017-0035.V46-3

Rosenblum, S., Goldblatt, H., \& Moin, V. (2008). The Hidden Dropout Phenomenon among Immigrant High-school Students: The Case of Ethiopian Adolescents in Israel-A Pilot Study. School Psychology International, 29(1), 105-127. https://doi.org/10.1177/0143034307088506

Rosenfeld, L. B., Richman, J. M., \& Bowen, G. L. (2000). Social support networks and school outcomes: The centrality of the teacher. Child and Adolescent Social Work Journal, 17(3), 205-226. https://doi.org/10.1023/A:1007535930286

Rumberger, R. W. (2001). Why Students Drop Out of School and What Can be Done. Retrieved from https://cloudfront.escholarship.org/dist/prd/content/qt58p2c3wp/qt58p2c3wp.pdf?t=msnxh4 [04.07.2018]

Rumberger, R. W. (2004). Why Students Drop Out of School. In G. Orfied (Ed.), Dropouts in America: Confronting the Graduation Rate Crisis (pp. 131-155). Cambridge: Harvard Education Press.

Rumberger, R. W., \& Ah Lim, S. (2008). Why Students Drop Out of School: A Review of 25 Years of Research. Santa Barbara: University of California.

Sälzer, C. (2010). Schule und Absentismus. Individuelle und schulische Faktoren für jugendliches Schwänzverhalten [School and truancy. Individual and school related factors for the truant behavior of students]. Wiesbaden: Verlag für Sozialwissenschaften. https://doi.org/10.1007/978-3-531-92251-5

Schönbächler, M.-T. (2008). Klassenmanagement. Situative Gegebenheiten und personale Faktoren in Lehrpersonen- und Schülerperspektive [Classroom management. Situational circumstances and personal factors in the perspectives of teachers and students]. Bern: Haupt.

Shernoff, D. J., \& Schmidt, J. A. (2008). Further evidence of an engagement-achievement paradox among US high school students. Journal of Youth and Adolescence, 37(5), 564-580. https://doi.org/10.1007/s10964-007-9241-z

Stamm, M. (2007). Schulabsentismus: eine unterschätzte pädagogische Herausforderung [Truancy: An underestimated pedagogical challenge]. Die Deutsche Schule, 99(1), 50-61.

Stamm, M. (2012). Schulabbrecher in unserem Bildungssystem [School dropouts in our education system]. Wiesbaden: VS Verlag für Sozialwissenschaften. https://doi.org/10.1007/978-3-531-94287-2

Suárez-Orozco, C., Pimentel, A., \& Martin, M. (2009). The significance of relationships: Academic engagement and achievement among newcomer immigrant youth. Teachers College Record, 111(3), 712-749.

Sultana, R. G. (2006). Facing the Hidden Drop-out Challenge in Albania. Evaluation Report of Hidden Drop-out Project Piloted in Basic Education in 6 Prefectures of Albania (2001-2005). Tirana: UNICEF.

Uekawa, K., Borman, K., \& Lee, R. (2007). Student engagement in US urban high school mathematics and science classrooms: Findings on social organization, race, and ethnicity. The Urban Review, 39(1), 1-43. https://doi.org/10.1007/s11256-006-0039-1

Virtanen, T., Lerkkanen, M.-K., Poikkeus, A.-M., \& Kuorelahti, M. (2014). Student behavioral engagement as a mediator between teacher, family, and peer support and school truancy. Learning and Individual Differences, 36, 201-206. https://doi.org/10.1016/j.lindif.2014.09.001

Wang, M. T., \& Eccles, J. S. (2013). School context, achievement motivation, and academic engagement: A longitudinal study of school engagement using a multidimensional perspective. Learning and Instruction, 28, 12-23. https://doi.org/10.1016/j.learninstruc.2013.04.002

Wang, M. T., Willett, J. B., \& Eccles, J. S. (2011). The assessment of school engagement: Examining dimensionality and measurement invariance by gender and race/ethnicity. Journal of School Psychology, 49(4), 465-480. https://doi.org/10.1016/j.jsp.2011.04.001

Woolley, M. E., \& Bowen, G. L. (2007). In the context of risk: Supportive adults and the school engagement of middle school students. Family Relations, 56(1), 92-104. https://doi.org/10.1111/j.1741-3729.2007.00442.x

Yazzie-Mintz, E. (2010). Charting the path from engagement to achievement: A report on the 2009 High School Survey of Student Engagement. Bloomington, IN: Center for Evaluation \& Education Policy. 


\section{Copyrights}

Copyright for this article is retained by the author, with first publication rights granted to the journal.

This is an open-access article distributed under the terms and conditions of the Creative Commons Attribution license (http://creativecommons.org/licenses/by/4.0/). 